\title{
Análise da produção científica com a temática inclusão no ensino superior: reflexões sobre artigos publicados no período de 2016 a novembro de 2018
}

Analysis of scientific production with the theme inclusion in higher education: reflections on articles published in the period from 2016 to November 2018

Análisis de la producción científica con la temática inclusión en la educación superior: reflexiones sobre artículos publicados en el período de 2016 a noviembre de 2018

\section{* Jair de Oliveira}

Professor Doutor na Universidade Tecnológica Federal do Paraná, Cornélio Procópio, Paraná, Brasil. jair37@gmail.com - https://orcid.org/0000-0001-7847-698X

Recebido em 26 de dezembro de 2018

Aprovado em 05 de abril de 2019

Publicado em 03 de julho de 2019

\section{RESUMO}

Este estudo analisa a produção científica brasileira no que tange à temática da inclusão no ensino superior. É uma pesquisa de origem bibliográfica, que se caracteriza como um estudo descritivo e qualitativo, a qual analisou 36 artigos, selecionados a partir de uma consulta online nas páginas da Capes e do Google Acadêmico. Ao todo, foram encontradas 975 publicações que correspondiam ao tema da inclusão no ensino superior; no entanto, de acordo com a metodologia adotada neste estudo, foram excluídos os artigos que não correspondiam aos critérios de seleção. Assim, a análise dos dados consiste na observação dos 36 artigos selecionados. Dessa forma, direcionamos duas etapas para esta pesquisa: i) primeiramente, realizou-se um exame de estudos de revisão sistemática sobre a inclusão no ensino superior, com o objetivo de compor um conjunto de orientações para embasar a realização da etapa dois; ii) na sequência, realizou-se uma pesquisa de revisão sistemática sobre o tema, a qual compõe o grupo de pesquisa de mapeamento de campos do conhecimento e de avaliação de resultados obtidos por meio da pesquisa bibliográfica nos sites mencionados. Os resultados dessa etapa mostraram que a inclusão é um processo em construção e dependente do comprometimento dos professores envolvidos na formação inclusiva; assim, o aperfeiçoamento profissional, como a formação continuada, são elementos fundamentais na capacitação de professores e demais servidores, para que ocorra, de fato, a inclusão no meio universitário.

Palavras-chave: Inclusão; Ensino Superior; Produção científica. 


\section{ABSTRACT}

This study analyzes the Brazilian scientific production, regarding the topic of inclusion in higher education. It is a bibliographical research, characterized as a descriptive and qualitative study, which analyzed 36 articles, selected from an online consultation on the website of Capes and Google Scholar. In all, there were 975 publications that corresponded to the topic of inclusion in higher education, however, according to the methodology adopted in this study, articles that did not meet the selection criteria were excluded. Thus, the analysis of the data consists of the observation of the 36 articles selected. In this way, we conducted two steps for this research: i) Firstly, an examination of systematic review studies on inclusion in higher education was carried out, aiming to compose a set of guidelines to support the implementation of stage two; ii) a systematic review was carried out on the subject, which comprises the research group mapping fields of knowledge and evaluation of results obtained through bibliographic research on the sites mentioned. The results of this stage showed that inclusion is a process under construction and dependent on the commitment of teachers involved in inclusive training, so professional improvement, such as continuing education, are fundamental elements in the training of teachers and other employees, so that fact, the inclusion in the university environment.

Keywords: Inclusion; Higher education; Systematic review.

\section{RESUMEN}

Este estudio analiza la producción científica brasileña, en lo que se refiere a la temática de la inclusión en la enseñanza superior. Es una investigación de origen bibliográfico, se caracteriza como un estudio descriptivo y cualitativo, la cual analizó 36 artículos, seleccionados a partir de una consulta online en el sitio de Capes y de Google Académico. En total, se obtuvieron 975 publicaciones que correspondían al tema de la inclusión en la enseñanza superior, sin embargo, de acuerdo con la metodología adoptada en este estudio, se excluyeron los artículos que no correspondían con los criterios de selección. Por lo tanto, el análisis de los datos consiste en la observación de los 36 artículos seleccionados. De esta forma, dirigimos dos etapas para esta investigación: i) primero, se realizó un examen de estudios de revisión sistemática sobre la inclusión en la enseñanza superior, con el objetivo de componer un conjunto de orientaciones para basar la realización de la etapa dos; ii) en consecuencia, se realizó una investigación de revisión sistemática sobre el tema, la cual compone el grupo de investigación de mapeo de campos del conocimiento y de evaluación de resultados obtenidos por medio de la investigación bibliográfica en los sitios mencionados. Los resultados de esta etapa mostraron que la inclusión es un proceso en construcción y dependiente del compromiso de los profesores involucrados en la formación inclusiva, así el perfeccionamiento profesional, como la formación continuada, son elementos fundamentales en la capacitación de los profesores y demás servidores, para que así, el hecho, ocurra la inclusión en el medio universitario.

Palabras clave: Inclusión; Enseñanza superior; Revisión sistemática. 


\section{Introdução}

De acordo com Ghirardi (2004), "a inclusão digna passa pelo exercício soberano da cidadania". Sendo assim, a forma mais eficaz de promover a inclusão é inseri-la na escola, desde o nível fundamental até a formação superior. Nas palavras de Mantoan (2003) um dos caminhos para se promovê-la é a escola, uma vez que a escola é um dos primeiros espaços a acolher a pessoa com deficiência; por isso, é primaz, assegurar que, nesse recinto, os direitos das pessoas com deficiência sejam garantidos. Contudo, isso ainda não ocorre de modo efetivo (BORGES; PEREIRA, 2016). Esses hiatos, pouco a pouco, são preenchidos por meio de ações da sociedade e por políticas e ações de governo nos âmbitos federal, estadual e municipal (MANHÃES, 2010). Por exemplo, a promulgação da Lei oㅜ 13.409, de 28 de dezembro de 2016, sobre a reserva de vagas para pessoas com deficiência nos cursos técnico de níveis médio e superior das instituições federais de ensino, aumentou o número de estudantes com deficiência no sistema universitário brasileiro.

Desse modo, um dos principais desafios dos gestores escolares é lidar com as demandas individuais e coletivas desse público, pois as escolas e as universidades representam um dos pilares de uma sociedade que se democratiza e se transforma (TEZANI, 2009). Além da acessibilidade no ensino superior, isto é, oferecer a oportunidade do ensino universitário para pessoas com necessidades especiais, também se faz necessária a mudança na estrutura do local, como proporcionar um ambiente adaptado às pessoas com deficiências físicas, por exemplo, cadeirantes. É necessário que a universidade esteja preparada para receber tais alunos, pois requer mudanças em todas as dimensões da instituição. A inclusão requer mudanças de ordem pedagógica, de infraestrutura, de procedimento, de processos e de atendimento, situações que exigem dos gestores uma visão holística da sua unidade e integrada aos diversos níveis de ensino (DINIZ, 2017). Requer, também, a preparação das equipes de trabalho para atender essas demandas e para promover novas interações com as comunidades acadêmica e externa (CAVALCANTI, 2014).

Apresenta-se, pois, uma adaptação da problemática de Pereira et al. (2016), que constitui o problema da pesquisa: qual o panorama das pesquisas sobre a inclusão de estudantes com deficiência em instituições de ensino superior, de 2016 até 2018, considerando os resultados de estudos bibliométricos ou de revisão sistemática publicados 
sobre essa temática?. A partir dessa proposição e com base nas ideias de Pereira et al. (2016) definiu-se o objetivo geral: analisar a produção científica sobre a temática inclusão no ensino superior, no período de janeiro de 2016 até novembro de 2018.

A pesquisa está organizada em duas etapas: a primeira seção corresponde à avaliação dos trabalhos de revisão sistemática ou de estudos bibliométricos sobre a pessoa com deficiência e ensino superior. Na segunda etapa, realizaram-se análises da produção científica relevante sobre a temática "pessoa com deficiência e ensino superior". Também busca-se, a partir da análise dos dados e da observação dos resultados, contribuir para o entendimento da inclusão no nível universitário, visando, pois, incentivar a realização de estudos futuros.

\section{Inclusão no ensino superior}

As pesquisas e as discussões sobre inclusão seguiram os passos do movimento de expansão do acesso dos alunos com deficiência ao ensino regular, principalmente, a partir da promulgação da Política Nacional de Educação Especial na Perspectiva da Educação Inclusiva (PNEEPEI) (MEC, 2008). Primeiramente, elas foram direcionadas para o ensino fundamental; depois, para o ensino básico e, agora, para o ensino superior. Os níveis iniciais de educação receberam as primeiras pesquisas, e por isso, possuem um arcabouço teórico em pleno desenvolvimento (MICHELS, 2006; MENDES, 2008; HAYASHI, 2011; OLIVEIRA; DRAGO, 2012; TEIXEIRA, 2015; FREITAS; TEIXEIRA; RECH, 2016; FREITAS et al., 2016; FREITAS; SCHNECKENBERG, 2017); ao passo que, no nível superior de ensino, as experiências e as pesquisas de acolhimento e de ações para permanência dos alunos com deficiência, ainda, são incipientes (TEZANI, 2009). Também vale ressaltar que a produção de conhecimento desta temática está aquém da demanda, as quais se ampliaram pelos desdobramentos da PNEEPEI (PLETSCH; LEITE, 2017). Além disso, o acesso de estudantes com deficiência ao ensino superior depara-se com diversas demandas, distintas das modalidades de ensino infantil, básico e médio; por exemplo, atendimento às necessidades de deslocamento e locomoção, dado que nas universidades, eles precisam andar grandes distâncias entre salas de aulas, laboratórios, auditórios e bibliotecas (BORGES et al., 2017; PETTEN; ROCHA; BORGES, 2018).

Segundo relatórios do instituições brasileiras de ensino superior (INEP) $(2014,2016$, 2017), foram registradas 1.249 .324 matrículas nas 107 instituições federais de ensino superior, em 2016. Desse total, o número de alunos com necessidades especiais 
matriculados nas instituições federais é de 11.650 , representando $0,93 \%$ do total. Nos dados de matrículas de alunos com necessidades especiais na rede federal, de 2014 para 2016, observa-se um crescimento de 10.602 para 11.650, representando aumento percentual de aproximadamente $9,88 \%$. Além disso, no mesmo período, ocorreu um salto nas matrículas dos alunos que apresentam deficiências visuais, surdez, física, autismo infantil e uma acentuada diminuição do número de alunos com superdotação. No entanto, de 2016 para 2017, houve uma pequena diminuição no número de matrículas, para 10.667, equivalendo a uma retração de $8,43 \%$.

Em suma, existem contradições entre as demandas para inclusão no ensino superior e os serviços que são ofertados pelas instituições de ensino (SILVA; MARTINS, 2016; MIRANDA, 2017; CRUZ; SOUZA, 2017); por isso, são apresentadas, a seguir, as duas etapas desta pesquisa, cujos resultados poderão nortear a realização de novos estudos empíricos.

\section{Metodologia}

Esta pesquisa descritiva apresenta uma abordagem qualitativa e está organizada em duas etapas: (i) a partir do exame de trabalhos de revisão sistemática ou de estudos bibliométricos, propõe-se compor um conjunto de orientações para embasar a realização de pesquisas sobre inclusão no ensino superior; e (ii) realizar uma pesquisa de revisão sistemática ou estudo bibliométrico sobre essa temática. Essas duas modalidades compõem o grupo de pesquisa de mapeamento de campos do conhecimento e de avaliação de resultados de pesquisas (VOSGERAU, 2014).

O estudo de revisão sistemática é uma das modalidades de revisão, sendo um tipo de investigação científica de análise crítica sobre determinado tema, tendo como fonte de dados a literatura disponível. Para tanto, utiliza métodos explícitos e sistematizados para levantar, reunir e avaliar de forma crítica os resultados de diversos estudos primários. Busca acompanhar o curso científico de determinado tema em um período específico e contribui para disseminar informações científicas, esclarecer controvérsias e auxiliar profissionais na formulação de novas pesquisas (GALVÃO; PEREIRA, 2014; SAMPAIO; MANCINI, 2007; UNESP, 2015).

Enquanto o estudo bibliométrico caracteriza-se como investigação quantitativa de informação, originária da Biblioteconomia, busca avaliar objetivamente as atividades de produção e comunicação científica (FERREIRA, 2018; VOSGERAU, 2014), por meio da 
medição dos indicadores de disseminação do conhecimento (ARAÚJO, 2006). Possui como fontes de pesquisas materiais bibliográficos de diferentes tipos.

Assim, acrescenta-se, neste momento, a descrição metodológica do estudo. $\mathrm{Na}$ sequência, a execução da análise e a forma como é dividida: a primeira parte da pesquisa ocorreu de agosto a setembro de 2018, quando examinaram-se os trabalhos de revisão e de estudos bibliométricos sobre deficientes no ensino superior, publicados do ano de 2011 até o mês de agosto de 2018. Para a definição desse período, considerou-se que os materiais publicados antes de 2011 não atenderiam ao propósito dessa etapa do trabalho, qual seja, compor um conjunto de orientações para embasar a realização das pesquisas sobre inclusão no ensino superior, pois os artigos publicados após essa data já captariam o impacto do lançamento da Política Nacional de Educação Especial na Perspectiva da Educação Inclusiva (BRASIL, 2008) e da promulgação do Estatuto da Pessoa com Deficiência (BRASIL, 2015). Assim, essa etapa foi organizada em três fases: (i) levantamento do material; refinamento; e seleção dos artigos.

$\mathrm{Na}$ primeira fase, levantamento, foram definidos os termos para compor as combinações de palavras-chave, isto é, pessoa com deficiência, ensino superior, análise sistemática, revisão sistemática e estudo bibliométrico. A seguir, utilizou-se a base de dados disponível no periódico da Capes, na opção Busca por Assunto/Busca Avançada para pesquisa dos artigos publicados em periódicos. Além das bases disponíveis na página da Capes, foram verificados os artigos publicados em duas revistas especializadas: a Revista Brasileira de Educação Especial e a Revista Educação Especial. Inicialmente, utilizaram-se os termos em português, uma vez que o interesse de pesquisa é o cenário universitário brasileiro, no entanto, foram realizadas buscas com os respetivos termos em inglês, a fim de verificar a possibilidade de publicação do material de interesse desta etapa da pesquisa, em periódicos internacionais, nessa busca utilizou-se o Google Acadêmico.

Na segunda, refinamento, foram feitas as leituras de títulos, resumos e palavras-chave dos resultados da fase 1 e a classificação dos artigos pertinentes aos propósitos desta etapa. O principal critério para apontamento como pertinente foi o vínculo com o ensino superior e pessoa com deficiência. Esta etapa ocorreu de outubro a novembro de 2018, quando se realizou uma Revisão Sistemática da literatura sobre deficientes e ensino superior, considerando as orientações constantes no Quadro 4 (mais adiante). 
Na terceira, seleção, procedeu-se à leitura cuidadosa dos conteúdos dos artigos considerados como pertinentes na fase 2 .

\section{Resultados da Pesquisa}

\section{Primeira etapa: identificação de lacunas}

$\mathrm{Na}$ primeira fase desta etapa, levantamento inicial, foram identificados 81 artigos. Após as leituras de títulos, resumos e palavras-chave desses artigos, obteve-se, como resultado, 13 artigos classificados como pertinentes. Em seguida, realizaram-se o exame dos conteúdos dos artigos selecionados e os respectivos fichamentos. Na sequência, ao final da apreciação pormenorizada desses artigos, oito pesquisas foram selecionadas para a realização do estudo da primeira etapa, conforme apresentado na Tabela 1.

Tabela 1 - Demonstrativo dos artigos selecionados

\begin{tabular}{|c|c|}
\hline Base de dados & Capes \\
\hline Levantamento inicial & 81 \\
\hline Refinamento inicial & 13 \\
\hline Selecionados para o trabalho & 8 \\
\hline
\end{tabular}

Fonte: dados da pesquisa.

Dos artigos que foram excluídos na fase de refinamento, merecem menções: o trabalho de Brito, Quirino e Porto (2013), a despeito desse material manter um vínculo com os termos de busca desta etapa da pesquisa, ele não apresentou uma descrição minuciosa do percurso metodológico e dos critérios utilizados para a realização da revisão sistemática ou estudo bibliométrico, e por isso não foi selecionado. Desconsiderou-se, também, o trabalho de Bueno (2013), o qual apesar de ser publicado em 2013, foi apresentado em um evento em 2008. Outro trabalho excluído, de grande envergadura, é a pesquisa de Brito e Zeppone (2013), estudo que foi apresentado em um evento e não atendeu a um dos requisitos da busca desta pesquisa, da publicação em periódicos. Ainda, outro trabalho relevante não considerado foi o de Wellichan e Souza (2017). Contudo, apesar de esses textos não serem aproveitados nesta pesquisa, mostraram a possibilidade da inclusão dos termos "mapeamento" e "balanço" na identificação de artigos quanto à realização de pesquisas semelhantes à realizada nesta etapa. Por isso, foi identificado e selecionado o trabalho de Araujo, Araujo e Araujo (2016), o qual foi incluído entre os oitos apresentados na Tabela 1.

Quanto ao número de artigos selecionados, entende-se que a quantidade alcançada é representativa para o interesse desta etapa da pesquisa, pois, como bem salientaram 
Silva et al. (2012), há uma escassez de pesquisa sobre a inclusão de aluno com deficiência no ensino superior. Além disso, um dos critérios para a seleção do artigo para a primeira etapa é a exigência de ser um estudo de revisão sistemática ou estudo bibliométrico. Assim, se por um lado, esse requisito limitou a quantidade de artigos selecionados, por outro contribui para atender precisamente o objetivo desta etapa da pesquisa, cujos resultados e discussões são apresentados a seguir.

O Quadro 1 apresenta os autores dos artigos selecionados e seus respectivos focos de estudos. Observa-se que todos os artigos possuem vínculo com o ensino superior. O primeiro foi publicado em 2012 e o último em 2017; contudo, percebe-se um lapso temporal de quatro anos do primeiro artigo para o segundo, de 2012 para 2016, quando o número de publicação aumentou para quatro e manteve-se em três no ano de 2017. Verificou-se que os autores desses artigos apresentaram uma única publicação; além disso, apenas o trabalho de Cabral (2017) citou três artigos apresentados na lista: Silva et al. (2012), Pereira et al. (2016) e Torres, Calheiros e Santos (2016).

Quadro 1- Resultado do levantamento da Etapa 1

\begin{tabular}{|l|l|l|}
\hline \multicolumn{1}{|c|}{ Autores } & \multicolumn{1}{c|}{ Foco do estudo } \\
\hline 1. & Silva et al. (2012) & A inclusão de estudantes com deficiência no ensino superior \\
\hline 2. & Pereira et al. (2016) & Inclusão de estudantes com deficiência no ensino superior \\
\hline 3. & Oliveira et al. (2016) & $\begin{array}{l}\text { A inclusão de pessoas com necessidades especiais no } \\
\text { ensino superior }\end{array}$ \\
\hline 4. & $\begin{array}{l}\text { Torres, Calheiros e } \\
\text { Santos (2016) }\end{array}$ & O processo de inclusão na educação superior brasileira \\
\hline 5. & $\begin{array}{l}\text { Araujo, Araujo e Araujo } \\
\text { (2016) }\end{array}$ & $\begin{array}{l}\text { Educação especial no ensino superior: contribuições e } \\
\text { perspectivas }\end{array}$ \\
\hline 6. & $\begin{array}{l}\text { Dussilek e Moreira (2017) } \\
\text { condições apresentadas aos estudantes com deficiência }\end{array}$ \\
\hline 7. & Cabral (2017) & $\begin{array}{l}\text { Inclusão do público-alvo da educação especial no ensino } \\
\text { superior brasileiro: histórico, políticas e práticas }\end{array}$ \\
\hline 8. & Mendes e Ribeiro (2017) & \begin{tabular}{l} 
Inclusão da pessoa com deficiência no ensino superior \\
\hline
\end{tabular}
\end{tabular}

Fonte: Elaborado pelo autor.

Conforme demonstrado no Quadro 2, não foram encontrados artigos com foco em Análise Bibliométrica ( $A B)$. Assim, todos os trabalhos selecionados foram classificados como de Revisão Sistemática. Essa ausência de trabalhos de AB chamou a atenção, pois, em pesquisas sobre pessoas com deficiência, a aplicação de análise bibliométrica está em franco crescimento (OLIVEIRA; MILL, 2016; FERREIRA et al., 2017). O período de busca aplicado pelos artigos selecionados abrangeu de 2001 até 2016 . A fonte principal de busca 
foi o portal da CAPES. Contudo, três trabalhos utilizaram bases da área de ciências da saúde: Silva et al. (2012), Oliveira et al. (2016) e Cabral (2017). Essa ampliação de base pode ser produtiva, pois dois desses trabalhos têm a atuação dos autores na área de saúde. Mendes e Ribeiro (2017) utilizaram a fonte de pesquisa mais restrita, com foco em dissertações e teses, refinada para a área de educação; ao passo que Cabral (2017), apesar da formação na área de educação, utilizou o maior número de bases, inclusive as bases de saúde. Como demonstrado no Quadro 2:

Quadro 2 - Fontes para as pesquisas

\begin{tabular}{|c|c|c|c|c|}
\hline & $\begin{array}{l}\text { Procedên- } \\
\text { cia }^{1}\end{array}$ & Autores & Período & Fonte da pesquisa \\
\hline 1. & $\mathrm{RS}$ & $\begin{array}{l}\text { Silva et al. } \\
(2012)\end{array}$ & $\begin{array}{c}2001 a \\
2012\end{array}$ & $\begin{array}{c}\text { Lilacs, Bireme, Scielo, Pepsic e Portal de } \\
\text { Periódicos da CAPES }\end{array}$ \\
\hline 2. & RS & $\begin{array}{l}\text { Pereira et } \\
\text { al. }(2016)\end{array}$ & $\begin{array}{c}2003 a \\
2013\end{array}$ & Periódicos da Capes \\
\hline 3. & RS & $\begin{array}{l}\text { Oliveira et } \\
\text { al. }(2016)\end{array}$ & $\begin{array}{c}2005 a \\
2014\end{array}$ & $\begin{array}{c}\text { Lilacs, Scielo, Cochrane, Medline e } \\
\text { PubMed }\end{array}$ \\
\hline 4. & RS & $\begin{array}{l}\text { Torres, } \\
\text { Calheiros e } \\
\text { Santos } \\
(2016)\end{array}$ & $\begin{array}{l}2007 a \\
2014\end{array}$ & Portal de Periódicos da CAPES \\
\hline 5. & RS & $\begin{array}{l}\text { Araujo, } \\
\text { Araujo e } \\
\text { Araujo } \\
(2016)\end{array}$ & $\begin{array}{l}2010 a \\
2014\end{array}$ & $\begin{array}{l}\text { Revista Brasileira de Educação Especial } \\
\text { (RBEE) }\end{array}$ \\
\hline 6. & RS & $\begin{array}{l}\text { Cabral } \\
(2017)\end{array}$ & $\begin{array}{l}2006 a \\
2016\end{array}$ & $\begin{array}{l}\text { Capes, Scielo, Periódicos Eletrônicos de } \\
\text { Psicologia, Literatura Científica e Técnica } \\
\text { da América Latina e Caribe e Centro } \\
\text { Latino-Americano e do Caribe de } \\
\text { Informação em Ciências da Saúde }\end{array}$ \\
\hline 7. & RS & $\begin{array}{l}\text { Mendes e } \\
\text { Ribeiro } \\
(2017)\end{array}$ & $\begin{array}{l}2007 a \\
2015\end{array}$ & $\begin{array}{l}\text { Dissertações e Teses dos Programas de } \\
\text { Pós-Graduação em Educação, por meio do } \\
\text { BDTD }^{1} \text { e o Banco de Teses e } \\
\text { Dissertações da Capes }\end{array}$ \\
\hline 8. & RS & $\begin{array}{l}\text { Dussilek e } \\
\text { Moreira } \\
(2017)\end{array}$ & $\begin{array}{l}2008 a \\
2015\end{array}$ & $\begin{array}{c}\text { Google Acadêmico } \\
\text { Periódicos qualificados como: } \\
\text { A1, A2, B1 ou B2 }\end{array}$ \\
\hline
\end{tabular}

Fonte: Elaborado pelo autor.

Os descritores e/ou termos utilizados nos procedimentos de busca são apresentados no Quadro 3. Pereira et al. (2016) e Dussilek e Moreira (2017) usaram apenas termos em inglês; Oliveira et al. (2016) utilizaram termos em inglês e espanhol, além do português. Cabral (2017) utilizou o maior conjunto de descritores e Mendes e Ribeiro (2017) utilizaram as denominações dos descritores tanto no singular, quanto no plural. Aliás essa é uma sugestão pertinente, pois, segundo esses autores, em alguns casos a inclusão do plural

\footnotetext{
${ }^{1}$ BDTD = Biblioteca Digital Brasileira de Teses e Dissertações;
} 
ampliava os resultados das buscas. Ao passo que Dussilek e Moreira (2017) ressaltaram a importância do uso das aspas e dos conectores lógicos, nesse caso o "and".

Quadro 3 - Procedimento das pesquisas

\begin{tabular}{|c|c|c|}
\hline & Autores & Descritores/palavras chaves \\
\hline 1. & Silva et al. (2012) & Não encontrado \\
\hline 2. & Pereira et al. (2016) & $\begin{array}{l}\text { Higher education, handicapped students, disabled, university, } \\
\text { disabled students, disabilities, students with disabilities e inclusion. }\end{array}$ \\
\hline 3. & Oliveira et al. $(2016)^{2}$ & $\begin{array}{l}\text { Education Higher, Mainstreaming Educatione Disabled Personse, } \\
\text { Educação Superior, Inclusão, Educacional e Pessoas com } \\
\text { Deficiência, Educación Supeior, Propensíon Educación e Personas } \\
\text { com Discapacidad. }\end{array}$ \\
\hline 4. & $\begin{array}{l}\text { Torres, Calheiros e Santos } \\
\qquad(2016)^{3}\end{array}$ & $\begin{array}{l}\text { Educação superior, Professores de Educação superior, Instituições } \\
\text { de Ensino Superior, Ensino Superior, Educação Especial e } \\
\text { Educação Inclusiva. }\end{array}$ \\
\hline 5. & $\begin{array}{l}\text { Araujo, Araujo e Araujo } \\
(2016)\end{array}$ & Não encontrado. \\
\hline 6. & Cabral (2017) & $\begin{array}{l}\text { Educação Superior, Universidade, Universitário, Instituições de } \\
\text { Ensino Superior, Ensino Superior, Educação Especial, Educação } \\
\text { Inclusiva, Inclusão, Acessibilidade, Acesso, Ingresso, Permanência, } \\
\text { Deficiência, Necessidades especiais, Necessidades Educacionais } \\
\text { Especiais, Público-Alvo e Docentes. }\end{array}$ \\
\hline 7. & Mendes e Ribeiro $(2017)^{4}$ & $\begin{array}{l}\text { Acadêmico com deficiência e ensino superior, estudante com } \\
\text { deficiência e ensino superior e pessoas com deficiência e ensino } \\
\text { superior. }\end{array}$ \\
\hline 8. & Dussilek e Moreira (2017) & $\begin{array}{l}\text { "Deficiência" and "deficiente" and "universidade" and "inclusão" } \\
\text { and "acessibilidade" and "ensino superior". }\end{array}$ \\
\hline
\end{tabular}

Ao avaliar os procedimentos metodológicos aplicados pelos artigos selecionados, todos de Revisão Sistemática, de um modo geral eles seguiram uma sequência semelhante para a seleção dos seus respectivos materiais de análise (publicações), mas entende-se que o trabalho de Pereira et al. (2016) foi o que estabeleceu um conjunto de procedimento mais próximo aos propósitos desta pesquisa. Esses autores, além de definirem uma questão inicial de pesquisa, inseriram um teste de relevância para a seleção dos artigos. Nesse procedimento, dois avaliadores com conhecimento na área, por meio de apontamentos em um questionário, posicionaram-se positiva ou negativamente sobre a relevância dos artigos identificados na etapa anterior, com o objetivo da respectiva pesquisa. Os passos constantes do trabalho de Pereira et al. (2016) são: (i) definir uma

\footnotetext{
2 Uso de descritores controlados e não controlados. Segundo os autores: "Um descritor controlado refere-se especificamente à área de ciências na saúde, com o fim de representar os assuntos dos documentos e para serem utilizados como ferramenta de busca de artigos científicos..." (OLIVEIRA et al., 2016, p. 302).

${ }^{3}$ Extraído do Thesaurus Brasileiro da Educação (Brased).

${ }^{4}$ Descritores utilizados tanto no singular, quanto no plural.
} 
questão de pesquisa; (ii) definir os descritores; (iii) definir a ferramenta de busca; (iv) definir o período de busca; (v) aplicação dos critérios de inclusão/exclusão; (vi) aplicação de um teste de relevância dos artigos; (vii) delimitação das variáveis a serem investigadas; (viii) coleta e categorização dos dados; e (ix) apresentação dos resultados.

No que se refere aos resultados dos artigos e as sugestões para futuras pesquisas, Silva et al. (2012) apontaram que as diretrizes legais para acesso e permanência dos alunos não são aplicadas de modo efetivo e citaram que as principais causas estão relacionadas ao despreparo dos professores, à falta de conhecimento da população universitária, às implementações de estratégias pedagógicas e às limitações das infraestruturas; contudo, nesse texto não foram encontradas sugestões de novos trabalhos. Já a pesquisa de Pereira et al. (2016) ressaltou a importância de que alunos com deficiência reportem, no ato da matrícula, a sua situação, pois é importante notificar a instituição, para que ela se prepare para atender as suas demandas. Porém, eles apontam que, mesmo assim, os alunos estão insatisfeitos com as ações e com as condições ofertadas pelas instituições de ensino. Para novos estudos, recomendam verificar qual o panorama das pesquisas sobre inclusão no ensino superior. Para Araujo, Araujo e Araujo (2016), a preocupação com o ingresso do aluno com deficiência no ensino superior deveria começar na educação infantil, para que, quando alcance a universidade, consiga concluir o curso, com as capacidades necessárias para o exercício da profissão.

Oliveira et al. (2016), por sua vez, constataram que a educação inclusiva em relação às pessoas adultas recebe pouca atenção dos pesquisadores e que os trabalhos atualmente realizados são voltados mais para a assistência em saúde e muito pouco para a educação inclusiva. Desse modo, sugerem verificar se as Instituições de Ensino Superior (IES) estão preparadas para a inclusão de pessoas com necessidades especiais. Torres, Calheiros e Santos (2016) apontaram a escassez de trabalhos sobre inclusão no ensino superior; porém, com um crescente interesse a partir de 2014. Assim, indicaram a necessidade de identificar as principais dificuldades dos alunos com deficiência no ensino superior. Similarmente, Dussilek e Moreira (2017) relatam que, apesar de as políticas públicas assegurarem ao aluno com deficiência o direito ao acesso no ensino superior, existe um descompasso entre o que essas propostas anunciam e a realidade dos alunos, quanto à permanência e à conclusão da sua formação. Nesse sentido, eles sugerem 
explorar quais seriam essas dificuldades de promover a inclusão, bem como a conclusão da sua formação.

Os resultados de Cabral (2017) estão agrupados em cinco dimensões para a realização de pesquisa no ensino superior: (I) Políticas de Acesso e Permanência; (II) Percurso Acadêmico do Estudante Público-Alvo da Educação Especial; (III) Identificação e Identidade do Estudante Público-Alvo da Educação Especial; (IV) Construção da Cultura Inclusiva; e (V) Impeditivos para a Permanência e Sucesso Acadêmico. Como resultados finais, apontam que é necessário transcender as práticas isoladas e evitar a centralidade atores, ambientes ou estratégias - no processo de construção de uma cultura universitária sob a perspectiva inclusiva. Como sugestão, o autor propõe avaliar os motivos e as consequências das ações centralizadas e, ainda, as oportunidades de uma eventual descentralização.

Por fim, Mendes e Ribeiro (2017) apontaram um aumento significativo no número de publicações e uma ampliação dos temas abordados em dissertações e teses, mas poucos estudos de abordagem quantitativa. A maioria das pesquisas que eles investigaram é ancorada pelo estudo de caso, pela entrevista na coleta de dados e pela análise de conteúdo como instrumento para o tratamento dessas informações. Eles propuseram, como sugestão de pesquisa, a realização de estudos que possam contribuir para os avanços, não apenas em termos da educação, mas acrescido da inclusão social das pessoas com deficiência a partir do ambiente universitário. 
Quadro 4 - Síntese da Etapa I

\begin{tabular}{|c|c|}
\hline \multirow{2}{*}{ Categorias } & Revisão Sistemática (RS) \\
\hline & Sugestões para conduzir a etapa 2 da pesquisa \\
\hline $\begin{array}{l}\text { Abrangência temporal - } \\
\text { não atendida pelas } \\
\text { demais pesquisas }\end{array}$ & Após 2016 \\
\hline Objetivo Geral & $\begin{array}{l}\text { Analisar a produção científica sobre inclusão das pessoas com deficiência no } \\
\text { ensino Superior (CABRAL, 2017; FERREIRA et al., 2017). }\end{array}$ \\
\hline Questões de pesquisa & $\begin{array}{l}\text { Qual o panorama das pesquisas sobre a inclusão de estudantes com } \\
\text { deficiência nas instituições de ensino superior, considerando o que foi } \\
\text { publicado a partir de } 2016 \text { até novembro de 2018? (PEREIRA et al., 2016). }\end{array}$ \\
\hline Procedimentos & $\begin{array}{l}\text { (1) Definir uma questão de pesquisa; (2) definir os descritores; (3) definir } \\
\text { ferramenta de busca; (4) definição do período de busca; (5) aplicação dos } \\
\text { critérios de inclusão/exclusão; (6) aplicação de um teste de relevância dos } \\
\text { artigos; (7) delimitação das variáveis a serem investigadas; (8) coleta e } \\
\text { categorização dos dados; e (9) apresentação dos resultados (PEREIRA et } \\
\text { al., 2016). }\end{array}$ \\
\hline Base de dados & Periódicos da CAPES. \\
\hline Fontes de pesquisa & Periódicos Nacionais, qualificados como A ou B. \\
\hline $\begin{array}{l}\text { Descritores } \\
\text { (singular e plural) }\end{array}$ & $\begin{array}{l}\text { Educação Superior, Universidade, Universitário, Instituições de Ensino } \\
\text { Superior, Ensino Superior, Educação Especial, Educação Inclusiva, Inclusão, } \\
\text { Acessibilidade, Acesso, Ingresso, Permanência, Deficiência, Necessidades } \\
\text { Especiais, Necessidades Educacionais Especiais, Público-Alvo e Docentes } \\
\text { (CABRAL, 2017) e Gestão Universitária (sugestão do autor). }\end{array}$ \\
\hline Categorias & $\begin{array}{l}\text { (1) Construção da Cultura Inclusiva; (2) Gestão Universitária; (3) } \\
\text { Identificação e Identidade do Estudante Público-Alvo da Educação Especial; } \\
\text { (4) Impeditivos para a Permanência e Sucesso Acadêmico (adaptado de } \\
\text { CABRAL, 2017); (5) Percurso Acadêmico do Estudante Público-Alvo da } \\
\text { Educação Especial; (6) Políticas de Acesso; e (7) Outros. }\end{array}$ \\
\hline
\end{tabular}

Fonte: Quadros 1, 2 e 3, apresentados neste trabalho. ${ }^{5}$

O Quadro 4 apresenta uma síntese dos artigos selecionados na Tabela 1, a qual norteou a realização da segunda etapa desta pesquisa, que será apresentada a seguir.

\section{Resultados da segunda etapa da pesquisa}

Para a condução desta etapa da pesquisa, de outubro a novembro de 2018, inicialmente preparam-se as combinações dos descritores e os seus respectivos códigos, conforme apresentado no Quadro 5. De posse dessa lista, iniciou-se a busca dos artigos relevantes, por meio do sítio periódicos da Capes, nas opções 'busca avançada', com o registro de busca conforme a combinação dos descritores, material apenas artigo, com o conector lógico "exato" e limitado pela data de início em 2016.

\footnotetext{
${ }^{5}$ Além das cinco categorias sugeridas por Cabral (2017), foi incluída mais duas: uma denominada (6) Gestão universitária, e (7) Outros, para inclusão de trabalhos que não estivessem classificados nas demais categorias e, principalmente, sobre as temáticas egressos e pós-graduação.
} 
Os resultados da busca sistemática identificaram 894 artigos, classificados em 20 classes de descritores. Desse total, 614 não atenderam aos objetivos deste artigo e 249 são repetitivos. Assim, após a análise, foram elencados 28 artigos, conforme o Quadro 5, que, posteriormente, foram classificados nos respectivos temas.

Quadro 5 - Composição da amostra de artigos publicados após 2016

\begin{tabular}{|c|c|c|c|c|c|c|}
\hline \multirow[b]{2}{*}{ Combinação de descritores } & \multirow{2}{*}{ Código } & \multirow{2}{*}{$1^{6}$} & \multicolumn{3}{|c|}{ Seleção } & \multirow{2}{*}{ SF } \\
\hline & & & NA & RE & Ex & \\
\hline 1. Acessibilidade e Ensino Superior & ACENS & 143 & 134 & 3 & 136 & 6 \\
\hline 2. Educacão Superior e Inclusão 177 & EDSUP & 177 & 3 & 167 & 170 & 7 \\
\hline 3. Educação Especial e Ensino Superior & EEESS & 62 & 44 & 12 & 56 & 6 \\
\hline 4. Educação Inclusiva e Ensino Superior & EIENS & 27 & 19 & 6 & 25 & 2 \\
\hline 5. Ensino Superior e Pessoa com Deficiência & ENPCD & 14 & 8 & 6 & 14 & 0 \\
\hline 6. Educação Superior e Pessoa com Deficiência & ESPCD & 7 & 1 & 1 & 2 & 5 \\
\hline 7. Gestão Universitária e Acessibilidade & GUACB & 5 & 5 & 0 & 5 & 0 \\
\hline 8. Gestão Universitária e Acesso & GUACE & 28 & 27 & 1 & 28 & 0 \\
\hline 9. Gestão Universitária e Educação Especial & GUEDE & 1 & 1 & 0 & 1 & 0 \\
\hline 10. Gestão Universitária e Educação Inclusiva & GUEDI & 2 & 2 & 0 & 2 & 0 \\
\hline 11. Gestão Universitária e Inclusão & GUINC & 13 & 13 & 0 & 13 & 0 \\
\hline $\begin{array}{l}\text { 12.Gestão Universitária e Necessidades } \\
\text { Especiais }\end{array}$ & GUNES & 1 & 1 & 0 & 1 & $\mathbf{0}$ \\
\hline $\begin{array}{l}\text { 13. Gestão Universitária e Pessoa com } \\
\text { Deficiência }\end{array}$ & GUPCD & 1 & 0 & 0 & 0 & 1 \\
\hline 14.Instituições de Ensino Superior e Inclusão & ISINC & 87 & 78 & 9 & 87 & 0 \\
\hline $\begin{array}{l}\text { 15. Instituições de Ensino Superior e Pessoa } \\
\text { com Deficiência }\end{array}$ & Is & 4 & 3 & 1 & 4 & 0 \\
\hline $\begin{array}{l}\text { 16. Necessidades Educacionais Especiais e } \\
\text { Ensino Superior }\end{array}$ & ES & 10 & 6 & 4 & 10 & 0 \\
\hline 17. Necessidades Especiais e Ensino Superior & NEENS & 31 & 29 & 2 & 31 & $\mathbf{0}$ \\
\hline 18.Necessidades Especiais e Universidade & NESUN & 126 & 124 & 2 & 126 & 0 \\
\hline $\begin{array}{l}\text { 19. Necessidades Educacionais Especiais e } \\
\text { Universidade }\end{array}$ & NEUNI & 38 & 2 & 36 & 38 & 0 \\
\hline 20.Universidade e Pessoa com Deficiência & UNPCD & 117 & 116 & 0 & 116 & 1 \\
\hline Totais & & 894 & 614 & 249 & 863 & 28 \\
\hline
\end{tabular}

Fonte: elaborado pelo Autor.

Os artigos selecionados foram validados nos meses de novembro e dezembro de 2018, por meio da aplicação de um questionário a dois especialistas, para confirmar se os artigos seriam pertinentes aos objetivos desta pesquisa. Os resultados das avaliações dos especialistas consideraram todos os artigos como válidos. Posteriormente, os artigos foram classificados por tema, conforme Quadro 6. Nesse arranjo, o tema com mais artigos selecionados foi Impeditivos para a Permanência e Sucesso Acadêmico, com 11 artigos, seguido de Construção da Cultura Inclusiva, com 5. Destaca-se que Gestão Universitária ficou com apenas um artigo e que o tema Identificação e Identidade do Estudante Público-

\footnotetext{
${ }^{6}$ I: Identificado; NA: Não atende o escopo da pesquisa; RE: Repetido; Ex: Excluído; SF: Selecionado ao Final.
} 
Alvo da Educação Especial (IIE) não recebeu nenhum e, por isso, não se encontra no Quadro 6.

Quadro 6 - Temas dos artigos

\begin{tabular}{|l|c|c|l|}
\hline \multicolumn{1}{|c|}{ Temas } & Código & Quant. & \multicolumn{1}{c|}{ Autores } \\
\hline Gestão Universitária & GEU & 1 & $\begin{array}{l}\text { Nenus e Magalhães (2016) e Freitas, Pfitscher } \\
\text { e Belan (2016). }\end{array}$ \\
\hline Outros & OUT & 2 & $\begin{array}{l}\text { Burci e Costa (2018) e Messerschmidt e Castro } \\
\text { (2016) }\end{array}$ \\
\hline $\begin{array}{l}\text { Percurso Acadêmico } \\
\text { do Estudante com } \\
\text { Deficiência }\end{array}$ & PAE & 3 & $\begin{array}{l}\text { Chahini (2016b), Fernandes (2016) e Santos e } \\
\text { Dantas (2017) }\end{array}$ \\
\hline Políticas de Acesso & POA & 4 & $\begin{array}{l}\text { Melo e Martins (2016), Almeida Júnior e } \\
\text { Fernandes (2016), Amorim, MMederios Neta e } \\
\text { Guimarães (2016) e Estácio e Almeida (2016) }\end{array}$ \\
\hline $\begin{array}{l}\text { Construção da Cultura } \\
\text { Inclusiva }\end{array}$ & CCI & 6 & $\begin{array}{l}\text { Chahini (2016a), Omote (2016), Sales, Moreira } \\
\text { e Couto (2016), Stroparo e Moreira (2016), } \\
\text { Dantas (2018) e Almeida e Ferreira (2018). }\end{array}$ \\
\hline $\begin{array}{l}\text { Impeditivos para a } \\
\text { Permanência e } \\
\text { Sucesso Acadêmico }\end{array}$ & IPA & 11 & $\begin{array}{l}\text { Silva e Martins (2016), Santana (2016), Moura, } \\
\text { Leite e Martins (2016), Martins e Silva (2016), } \\
\text { Pansanato, Rodrigues e Silva (2016), Candido, } \\
\text { Nascimento, Martins (2016), Selau, Damiani e } \\
\text { Costas (2017), Alexandrino et al. (2017), Ziliotto, } \\
\text { Souza e Andrade (2018), Nozu, Silva e Anache } \\
\text { (2018) e Sbrana e Carneiro (2018). }\end{array}$ \\
\hline \multicolumn{2}{|c|}{ Total } & $\mathbf{2 8}$ & \\
\hline
\end{tabular}

Fonte: elaborado pelo Autor.

Ao finalizar essa etapa, ressalta-se que a quantidade de artigos selecionados, 28, é decorrente de um longo processo de escolha; assim, entende-se que esse resultado possibilita a discussão atualizada sobre o panorama das pesquisas sobre a inclusão de estudantes com deficiência em instituições de ensino superior, evidentemente considerando as limitações de pesquisa desta natureza. Contudo, a pequena quantidade de artigos selecionados em alguns temas demostra que o campo de estudo ensino superior é carente de pesquisas acadêmicas publicadas em periódicos.

A seguir são apresentadas as discussões dos artigos selecionados por tema.

\section{Análise dos resultados da segunda etapa da pesquisa}

Os temas são apresentados em ordem crescente de quantidade; desse modo, 0 primeiro tema é sobre Gestão Universitária. Observa-se que, apesar de as instituições de ensino superior atenderem às recomendações legais, a aplicação das orientações normativas nas respectivas instituições ocorre de modo diferenciado. Dessa forma, um dos pilares para a melhoria da inclusão universitária é o trabalho do gestor e dos coordenadores de curso (NUNES; MAGALHAES, 2016), pois a direção poderá propor um modelo de gestão social, por meio da criação de espaços/momentos de discussão, com a participação 
de alunos com deficiência e da comunidade acadêmica, quando seria possível mobilizar todos os participantes da inclusão e utilizar instrumentos de gestão para acompanhar as implantações dessas ações (FREITAS; PFITSCHER; BELAN, 2016).

O segundo tema, denominado "Outros", abarca os trabalhos de cunho geral. Inicialmente, trata da educação a distância no ensino superior, para a inclusão de aluno com deficiência visual. Os resultados de Burci e Costa (2018) apontaram que, com o uso adequado de Tecnologia Assistiva e das Tecnologias Digitais de Informação e Comunicação, a educação a distância poderá contribuir com o processo de inclusão no ensino superior. Sendo, assim, os polos educacionais em que os alunos realizam suas atividades presenciais deverão estar preparados, tanto na disponibilidade de infraestrutura, como nos aspectos administrativos e na formação e preparação de professores/instrutores. Desse modo, visa à mediação e aos domínios das tecnologias necessárias para a inclusão dos alunos por meio da educação a distância. Outra tratativa presente neste tema é a inclusão na perspectiva do professor. Messerschmidt e Castro (2016) apontam que, apesar de os docentes receberem uma formação para lidarem com a inclusão, isso não é o suficiente; é necessário que essa formação seja contínua e atualizada.

Sobre o Percurso Acadêmico do Estudante com Deficiência no Ensino Superior, para Fernandes (2016), as universidades são espaços apropriados para se promover a inclusão, pois elas estariam a serviço da sociedade, no âmbito interno, assegurando aos alunos o direito à cidadania e, externamente, compartilhando e exportando exemplos para mobilizar os demais cidadãos. Além disso, a inclusão é um processo de aprendizagem coletivo, tanto para os alunos como para os demais membros da comunidade. Para Santos e Dantas (2017), as universidades precisam promover discussões coletivas para disponibilizar o suporte necessário aos estudantes - no caso do artigo deles, os surdos em seus percursos acadêmicos -, como a disponibilização de tecnologias assistivas e a qualificação docente. Segundo Chahini (2016b), a convivência com alunos com deficiência no ensino superior promove mudanças positivas nas atitudes sociais da comunidade acadêmica. No entanto, no percurso acadêmico, inúmeras demandas operacionais ainda não atendem de modo efetivo as necessidades dos alunos com deficiência.

Quanto a Políticas de Acesso, para Melo e Martins (2016) e para Amorim, MMederios Neta e Guimarães (2016), o Brasil possui um leque normativo que assegura aos estudantes com deficiência o direito à igualdade de oportunidades para o acesso e a permanência no 
ensino superior, bem como orientações para compor processos pedagógicos apropriados. Porém, segundo Almeida Júnior e Fernandes (2016) e Estácio e Almeida (2016), a acessibilidade no ensino superior ainda permanece no campo teórico, atendendo apenas em certa medida os requisitos exigidos para uma inclusão plena. Por esse cenário, pondera-se que é preciso ir além do que se faz atualmente nas universidades, em especial, a atuação dos gestores, pois eles devem assegurar a execução das políticas públicas, prover os recursos específicos e indicados para cada tipo de demanda dos alunos com deficiência, sejam elas de ordem material (equipamentos, tecnologias) ou pessoal. Os gestores devem promover a formação e a conscientização da comunidade acadêmica, disseminando valores e princípios inclusivos, prezando pela participação futura dos alunos com deficiência na vida econômica, política, social e cultural do país (MELO; MARTINS, 2016; ALMEIDA JÚNIOR; FERNANDES, 2016; AMORIM; MMEDERIOS NETA; GUIMARÃES, 2016; ESTÁCIO; ALMEIDA, 2016).

No tema Construção da Cultura Inclusiva, Dantas (2018) e Chahini (2016a) advogam que o compartilhamento do mesmo ambiente é propício para que os alunos com deficiência possam interagir com os demais colegas e alcançar a autonomia. Omote (2016) cita que, para que isso ocorra, é imprescindível enfrentar as situações desfavoráveis oriundas por crenças, sentimentos e atitudes em relação à pessoa com deficiência, situações estas muitas vezes veladas (ARAUJO; ARAUJO; ARAUJO, 2016) e que podem se configurar em estereótipos, o que só aumentaria os obstáculos para o aluno com deficiência (SALES; MOREIRA; COUTO, 2016). Para Chahini (2016a), atitudes desfavoráveis em relação à inclusão podem aumentar as dificuldades de praticá-la, ou seja, de oferecer a inclusão. Além disso, existe, ainda, um descompasso ideológico entre o que os envolvidos na inclusão exteriorizam e, de fato, o que fazem para garantir a permanência exitosa dos alunos com deficiência no ensino superior. Por isso, Omote (2016) ressalta que os cursos com conteúdo curriculares sobre inclusão, convivência e interação podem promover atitudes sociais favoráveis em relação à inclusão.

Almeida e Ferreira (2018), inicialmente, ressaltam que o registro de alunos com deficiência no ensino superior apresenta falhas e que o aumento dos números de matrículas ocorreu, em um primeiro momento, em virtude de um interesse crescente das instituições em identificar e registrar com mais precisão esses sujeitos nos sistemas de coletas de dados do Instituto Nacional de Estudos e Pesquisas Educacionais Anísio Teixeira 
Legislação (INEP). Na sequência, advogam que a inclusão está além da disponibilidade de mecanismos de ingresso e locomoção. Ela possui múltiplas dimensões e precisam ser atendidas para que o aluno com deficiência permaneça no ensino superior. Entre essas dimensões, a implementação de um modelo universal de alunos, quando as limitações atreladas à deficiência não são estigmatizadas, mas atendidas como situações inerentes a uma sociedade plural.

Impeditivos para a Permanência e Sucesso Acadêmico é o tema que apresenta maior número de artigos selecionados. Apesar da possibilidade de classificar os artigos em subtemas, manteve-se a proposta inicial, para efeitos desta pesquisa. Para a permanência dos alunos com deficiência no ensino superior, segundo Nozu, Silva e Anache (2018), é necessário ampliar os investimentos em infraestrutura e em materiais de apoio, em sistema de informação e na formação de profissionais. Destacam, ainda, que existe uma dissonância entre o que é de fato inclusão e o que é realizado pela equipe de gestão. Ziliotto, Souza e Andrade (2018) mostraram a existência de elevados índices de evasão escolar de alunos surdos ou com deficiência auditiva, desde os primeiros semestres dos cursos. Entre os motivos constam fatores extrínsecos às políticas de inclusão, como financeiros, pessoais, saúde e mudança de estado, horário de trabalho, retorno à instituição de origem e opção por outro tipo de curso, transferência, avaliação do curso e vestibular em outra instituição (ZILIOTTO; SOUZA; ANDRADE, 2018). De acordo com Sbrana e Carneiro (2018), para a efetividade do processo de inclusão, faz-se necessária, da parte dos docentes, uma prática que requer iniciativa e reconhecimento da importância da inclusão na Educação Superior. Há a necessidade da oferta de formação, mas, acima de tudo, empenho e interesse dos professores para responder às demandas da inclusão.

Candido, Nascimento, Martins (2016) salientam que existem muitos obstáculos ainda para a inclusão plena e que o professor apresenta um papel fundamental nesse processo; porém são imperativas a concepção e a execução de uma projeto pedagógico coerente e comprometido com a inclusão. Também deve-se proporcionar ao docente uma formação que o auxilie a lidar da melhor forma possível com as necessidades individuais dos alunos com deficiência. Pansanato, Rodrigues e Silva (2016) indicaram que as ações promovidas pela instituição de ensino superior por eles pesquisada, relacionadas, entre outras, como ações iniciais, acesso ao material didático adaptado e alternativo e adaptações curriculares, atenderam as demandas de um egresso cego, uma vez que o aluno apresentou domínio 
das exigências do curso de formação. No entanto, na mesma linha de pesquisa, Selau, Damiani e Costas (2017) apontaram que existem obstáculos à inclusão de alunos cegos, "concernentes a aspectos institucionais, tendo como estratégia o investimento no ingresso e na permanência do aluno cego e concernentes a relações com professores" (SELAU; DAMIANI; COSTAS. 2017, p. 434-437). Alexandrino et al. (2017, p. 6-7) marcaram, como dificuldades:

\footnotetext{
"falta de materiais de estudo e avaliação adequada (Braile), falta de acessibilidade no prédio da instituição, falta de comunicação entre os docentes e funcionários da universidade para resolução dos problemas, bem como a falta de compreensão e medidas da gestão para melhorar o atendimento educacional" (ALEXANDRINO et al., 2017, p. 6-7).
}

Porém, uma inclusão plena também depende da iniciativa e de ações do próprio sujeito (SELAU; DAMIANI; COSTAS, 2017). Silva e Martins (2016) apresentam uma proposta de pesquisa sobre o que dizem os estudantes com deficiência, todavia, ainda sem os devidos resultados. Para Santana (2016), como a inclusão universitária é um fenômeno recente, ainda há uma distância entre a teoria e a prática; porém, com o tempo, essa distância diminuirá. A situação dos alunos surdos no ensino superior parece não ser diferente da realidade dos surdos na educação básica no Brasil. Ou seja, embora haja políticas públicas para apoiar a inclusão do surdo, na prática os recursos financeiros não seriam suficientes, assim como há escassez de profissionais qualificados envolvidos no processo.

Moura, Leite e Martins (2016) assinalaram que os alunos com deficiência reconhecem a importância do ingresso no ensino superior, mas não possuem uma compreensão completa sobre o funcionamento do ensino superior para o seu ingresso. Esses autores ressaltam que um dos elementos primordiais para facilitar a ambientação é a presença de um intérprete de Libras. Martins e Silva (2016) defendem que existem ações institucionais; entretanto, elas precisam atender plenamente às demandas específicas dos alunos com deficiência em relação às práticas e à mediação pedagógicas, observando a importância da formação continuada dos docentes.

Concluindo este tópico, ressalta-se que a categorização por tema, proposta no Quadro 6, é uma tentativa de organização dos trabalhos e não de autores. Ela não está finalizada, está em construção e, por isso, pode apresentar incongruências, sem limitar a sua aplicação. 


\section{Considerações finais}

Em uma avaliação geral dos resultados, entende-se que o papel do gestor universitário é fundamental nesse processo, pois é por meio do seu trabalho de alocação e aplicação de recursos financeiros que os planos são executados. Além disso, o cerne para a efetiva inclusão é o comprometimento da direção das instituições com as ações inclusivas.

Ao longo das discussões, observou-se que o atual arcabouço normativo atende satisfatoriamente às demandas para inclusão; no entanto, é na sua operacionalização que se encontram as maiores dificuldades. As instituições não desenvolvem as ações de inclusão de modo análogo. Elas possuem especificidades e capacidades orçamentárias dessemelhantes; por isso, tratam as demandas de modos díspares. Vários instrumentos de avaliação já verificam a existência dos mecanismos de inclusão; contudo, às vezes eles apenas checam a sua presença e não se estão atendendo satisfatoriamente a todas as necessidades dos alunos com deficiência. Então, em uma primeira medida, propõe-se não apenas verificar, mas diagnosticar se as ações, as práticas, os equipamentos e a infraestrutura presentes nos espaços universitários atendem efetivamente à inclusão, isto é, examinar o grau de efetividade dessas estruturas e ações.

Outra situação que merece atenção é a educação a distância. Nessa modalidade, os desafios são semelhantes aos dos cursos presenciais, seja quando os alunos com deficiência utilizam o contato a distância, seja quando da presença nos polos de estudo presenciais. Ressalta-se a necessidade de viabilizar a interação social, tanto no modelo presencial como a distância, pois, como característica do ensino superior, ela contribui para o desenvolvimento pessoal e a autonomia do aluno.

Outro ponto relevante detectado no estudo é o papel do professor. Foi quase unânime a ideia de que o elo principal na cadeia de atendimento ao aluno com deficiência é o professor. Por isso, citou-se a necessidade da formação do professor. Entretanto, mostrouse imprescindível que a formação seja continuada, tanto no ensino presencial quanto no ensino a distância. Ou seja, uma formação realmente contínua dos mediadores, em vez de apenas ofertas de cursos pontuais. Apesar dessa proeminência do professor, todos os envolvidos precisam estar preparados para atender os alunos com deficiência, desde o porteiro até o reitor/diretor da instituição de ensino. 
Em suma, o insucesso, a insegurança, os receios compõem a vida acadêmica de todos os alunos; os amadurecimentos emocional e intelectual devem estar presentes no cotidiano universitário. Então, os alunos com deficiência vivem as mesmas experiências dos demais alunos. Contudo, eles possuem singularidades que precisam ser atendidas satisfatoriamente para que, ao final do curso, sintam-se preparados profissionalmente.

Este trabalho demostrou um panorama das pesquisas sobre inclusão e ensino superior. Identificou-se a carência de estudos bibliométricos; portanto, sugere-se a realização de pesquisas dessa natureza, principalmente, a partir de 2016.

\section{Referências}

ALEXANDRINO, E. G. et al. Desafios dos alunos com deficiência visual no ensino superior: um relato de experiência. Cinergis, v. 18, n. 1, p. 1-7, 2017.

ALMEIDA JÚNIOR, C. B.; FERNANDES, S. Políticas de acessibilidade no ensino superior: desafios institucionais. ESTÁCIO, Marcos André Ferreira; ALMEIDA, Diana Andreza Rebouças. PEOPLE WITH DISABILITIES IN HIGHER EDUCATION. Journal of Research in Special Educational Needs, v. 16, p. 836-840, 2016.

ALMEIDA, J. G. A.; FERREIRA, E. L. Sentidos da inclusão de alunos com deficiência na educação superior: olhares a partir da Universidade Federal de Juiz de Fora. Psicologia Escolar e Educacional, v. 22, n. spe, p. 67-75, 2018.

AMORIM, É. G.; MMEDERIOS NETA; GUIMARÃES, J. A deficiência em foco nos currículos de graduação da UFRN: uma abordagem histórica (1960-2015). HOLOS, v. 2, p. 231-248, 2016.

ARAÚJO, C. A. A. Bibliometria: evolução histórica e questões atuais. Em questão, v. 12, n. 1, p. 11-32, 2006.

ARAUJO, D. A. C.; ARAUJO, C. C. C.; ARAUJO, E. L. Educação especial no ensino superior: contribuições e perspectivas. Revista lbero-Americana de Estudos em Educação, v. 11, n. 25, p. 503-515, 2016.

BORGES, J. A. S.; PEREIRA, A. C. C. O estado da arte sobre políticas públicas para pessoas com deficiência no brasil: dialogando sobre transversalidade e educação. Revista do serviço público, v. 67, n. 4, p. 555-574, 2016.

BORGES, M. L. et al. Desafios institucionais à inclusão de estudantes com necessidades Educativas Especiais no Ensino Superior. Revista Portuguesa de Educação, v. 30, n. 2, p. 7-31, 2017.

BRASIL. Lei no 13.146, de 6 de julho de 2015. Institui a Lei Brasileira de Inclusão da Pessoa com Deficiência (Estatuto da Pessoa com Deficiência). Brasília. Casa Civil, 2015. 
BRASIL. Secretaria de Educação Especial. Política Nacional de Educação Especial na Perspectiva da Educação Inclusiva. Brasília, DF, jan. 2008. [Documento elaborado pelo Grupo de Trabalho nomeado pela portaria n. 555/2007, prorrogada pela portaria n. 948/2007.

BRITO, A.E.C.A.; QUIRINO, D.L.C.; PORTO, L.C.M. Educação especial e inclusiva no ensino superior. Revista Educação, v.16, n.20-21, p.14-20, 2013.

BRITO, J.; ZEPPONE, Rosimeire Maria Orlando. Mapeamento de Teses e Dissertações sobre a inclusão de pessoas com deficiência no Ensino Superior no Brasil. Encontro da Associação Brasileira de Pesquisadores em Educação Especial, v. 8, 2013.

BUENO, J. G. S. Deficiência e ensino superior: balanço das dissertações e teses brasileiras (1987/2006). In: CHICON, J. F.; DRAGO, R.; VICTOR, S. L. (Orgs.). A educação inclusiva de crianças, adolescentes, jovens e adultos: avanços e desafios. Vitória: Edufes, 2013.

BURCI, T. V. L.; COSTA, M. L. F. Inclusão de pessoas com deficiência visual na educação a distância. Acta Scientiarum, v. 40, n. 2, p. e32212, 2018.

CABRAL, Leonardo Santos Amâncio. Inclusão do público-alvo da Educação Especial no Ensino Superior brasileiro: histórico, políticas e práticas/Inclusion of Special Education's target audience in Brazilian Higher Education: History, policies and practices. Revista de Educação PUC-Campinas, v. 22, n. 3, p. 371-387, 2017.

CANDIDO, E. A. P.; NASCIMENTO, C. R. S.; MARTINS, M. F. A. Acessibilidade na educação superior também envolve o trabalho pedagógico. Revista Ibero-Americana de Estudos em Educação, v. 11, n. 2esp, p. 1017-1033, 2016.

CAVALCANTI, A.; V. O PAPEL DO GESTOR ESCOLAR NO PROCESSO DE INCLUSÃO. In.: ENCONTRO DE ENSINO, Pesquisa e Extensão. Anais... Presidente Prudente - SP. 2014

CHAHINI, T. H. C. Atitudes sociais em relação à inclusão de alunos (as) com deficiência na educação superior. Interfaces da Educação, v. 7, n. 19, p. 314-328, $2016 a$.

CHAHINI, T. H. C. Inclusão de alunos com deficiência na educação superior. Journal of Research in Special Educational Needs, v. 16, p. 598-602, $2016 \mathrm{~b}$.

CRUZ, C. L. P.; SOUZA, R. C. S. Urdidura da inclusão na universidade federal de Sergipe. Encontro Internacional de Formação de Professores e Fórum Permanente de Inovação Educacional, v. 10, n. 1, 2017.

DANTAS, T. C. Experiência de pessoas com deficiência no ensino superior: um olhar sobre a vivência de empoderamento e autoadvocacia. Crítica Educativa, v. 1, n. 2, p. 82-97, 2015. 
DINIZ, M. Inclusão de pessoas com deficiência e/ou necessidades específicasAvanços e desafios. Autêntica, 2017.

DUSSILEK, C. A.; MOREIRA, J. C. C. Inclusion in higher education: a systematic review of the conditions presented to students with disabilities. Research, Society and Development, v. 6, n. 4, p. 317-341, 2017.

ESTÁCIO, M. A. F.; ALMEIDA, D. A. R. People with disabilities in higher education. Journal of Research in Special Educational Needs, v. 16, p. 836-840, 2016.

FERNANDES, Z. B. Universidade Inclusiva:(Trans) Formação e Cidadania. Journal of Research in Special Educational Needs, v. 16, p. 1067-1070, 2016.

FERREIRA, A. G. C. Bibliometria na avaliação de periódicos científicos. DataGramaZero, v. 11, n. 3, p. A05, 2010. Disponível em: http://www.brapci.inf.br/v/a/8927. Acesso em: 06 Out. 2018.

FERREIRA, N. C. S. et al. Estudo bibliométrico sobre a política educacional para pessoas com deficiência entre 1997 e 2014 (Bibliometric study about educational policies for people with disabilities, between 1997 to 2014). Revista Eletrônica de Educação, v. 11, n. 3, p. 804-816, 2017.

FREITAS, F. P. M. et al. A formação do gestor escolar e o conceito de inclusão no Programa Educação inclusiva: Direito a diversidade. Revista Espacios, v. 37, n. 33, 2016.

FREITAS, F. P. M.; SCHNECKENBERG, M. Inclusão e a formação para atuação do gestor escolar. REPPE-Revista de Produtos Educacionais e Pesquisas em Ensino, v. 1, n. 1, p. 79-101, 2017.

FREITAS, K. E.; PFITSCHER, E. D.; BELAN, A. B. Análise de Acessibilidade: Aplicação Parcial do Modelo Sicogea em um Centro de Ensino de uma Instituição Federal de Ensino. Revista de Gestão Ambiental e Sustentabilidade: GeAS, v. 5, n. 3, p. 120-134, 2016.

FREITAS, S. N.; TEIXEIRA, C. T.; RECH, A. J. D. Alunos com deficiência em situação de acolhimento institucional: desafios para a gestão e a inclusão escolar. Revista lberoAmericana de Estudos em Educação, v. 11, n. 4, p. 2104-2124, 2016.

GALVÃO, T. F.; PEREIRA, M. G. Revisões sistemáticas da literatura: passos para sua elaboração. Epidemiologia e Serviços de Saúde, v. 23, p. 183-184, 2014.

GHIRARDI, M. I. G. Trabalho e deficiência: as cooperativas como estratégia de inclusão s ocial. Rev. Ter. Ocup. v. 15, n. 2, p. 49-54, maio/ago., 2004.

HAYASHI, M. C. P. I. Múltiplos olhares sobre a produção do conhecimento em educação especial. Revista Diálogo Educacional, v. 11, n. 32, 2011. 
Instituto Nacional de Estudos e Pesquisas Educacionais Anísio Teixeira [INEP] (2014). Censo da Educação Superior. 2014. Acessado: 20 nov. 2018. Disponível: http://portal.inep.gov.br/web/guest/sinopses-estatisticas-da-educacao-superior.

Instituto Nacional de Estudos e Pesquisas Educacionais Anísio Teixeira [INEP] (2017). Censo da Educação Superior. 2017. Acessado: 20 nov. 2018. Disponível: Lhttp://portal.inep.gov.br/web/guest/sinopses-estatisticas-da-educacao-superior

MANHÃES, V. S. Breve análise da legislação das políticas públicas de empregabilidade para pessoas com deficiência. Cadernos gestão pública e cidadania, v. 15, n. 57, São Paulo, 2010.

MANTOAN, M. T. E. Inclusão escolar: o que é? Por quê? Como fazer?. Summus Editorial, 2003.

MARTINS, L. M. S. M.; SILVA, L. G. S. Trajetória acadêmica de uma estudante com deficiência visual no ensino superior. Revista Educação em Questão, v. 54, n. 41, p. 251274, 2016.

MEC. Ministério da Educação. Política nacional de educação especial na perspectiva da educação inclusiva. MEC/SEESP, jun. 2008.

MELO, F. R. L. V.; MARTINS, M. H. Legislação para estudantes com deficiência no ensino superior no Brasil e em Portugal: algumas reflexões. Acta Scientiarum - Education, v. 38, n. 3, p. 259-269, 2016.

MENDES, C. L.; RIBEIRO, S. M. INCLUSÃO DA PESSOA COM DEFICIÊNCIA NO ENSINO SUPERIOR: UM ESTUDO DA PRODUÇÃO ACADÊMICA NA ÁREA DA EDUCAÇÃO. Atos de Pesquisa em Educação, v. 12, n. 1, p. 189-206, 2017.

MENDES, E. G. - Pesquisas sobre inclusão escolar: Revisão da agenda de um grupo de pesquisa. Revista Eletrônica de Educação. São Carlos, SP: UFSCar, v.2, no. 1, p 3-25, jun. 2008.

MESSERSCHMIDT, D. W.; CASTRO, S. F. Docência com alunos com deficiência na universidade. Journal of Research in Special Educational Needs, v. 16, p. 394-398, 2016.

MICHELS, M. H. Gestão, formação docente e inclusão: eixos da reforma educacional brasileira que atribuem contornos à organização escolar. Revista Brasileira de Educação, v. 11, n. 33, p. 406-423, 2006.

MIRANDA, F. D. Educação especial em uma perspectiva inclusiva: aspectos históricos. Revista Educação Especial em Debate, v. 2, n. 4, p. 104-114, 2017.

MOURA, A. F.; LEITE, L. P.; MARTINS, S. E. S. O. Possibilidades de acesso à Universidade: estudantes surdos em questão. Journal of Research in Special Educational Needs, v. 16, p. 876-879, 2016. 
NOZU, W. C. S.; SILVA, A. M.; ANACHE, A. A. Permanência do aluno com deficiência no ensino superior: dados censitários sobre as universidades federais da região centrooeste. Revista Ibero-Americana de Estudos em Educação, v. 13, n. 6, p. 1421-1435, 2018.

NUNES, V. L. M.; MAGALHÃES, C. M. Gestão social na educação para pessoas com deficiência. HOLOS, v. 8, p. 355-365, 2016.

OLIVEIRA, A. A. S.; DRAGO, S. L. S. A gestão da inclusão escolar na rede municipal de São Paulo: algumas considerações sobre o Programa Inclui. Ensaio: Avaliação e Políticas Públicas em Educação, p. 347-372, 2012.

OLIVEIRA, C. D.; MILL, D. Acessibilidade, inclusão e tecnologia assistiva: um estudo bibliométrico. Revista Ibero-Americana de Estudos em Educação, v. 11, n. 3, p. 11691183, 2016.

OLIVEIRA, Ronaldo Queiroz de et al . A Inclusão de Pessoas com Necessidades Especiais no Ensino Superior. Rev. bras. educ. espec., Marília, v. 22, n. 2, p. 299-314, June 2016.

OMOTE, S. Atitudes em relação à inclusão no ensino superior. Journal of Research in Special Educational Needs, v. 16, p. 211-215, 2016.

PANSANATO, L. T. E.; RODRIGUES, L.; SILVA, C. E. Inclusão de estudante cego em curso de Análise e Desenvolvimento de Sistemas de uma instituição pública de ensino superior: um estudo de caso. Revista Educação Especial, v. 29, n. 55, 2016.

PEREIRA, R. R. et al. Inclusão de estudantes com deficiência no ensino superior: uma revisão sistemática. Revista Educação Especial, v. 1, n. 1, p. 147-160, 2016.

Petten, A. M. V. N. V.; ROCHA, T. C. C.; BORGES, A. A. P. Política de cotas na universidade federal de minas gerais: uma análise do perfil dos alunos com deficiência. Revista Diálogos e Perspectivas em Educação Especial, v. 5, n. 1, p. 127-140, 2018.

PLETSCH, M. D.; LEITE, L. P. Análise da produção científica sobre a inclusão no Ensino Superior brasileiro. Educar em Revista, p. 87-106, 2017.

SALES, N. Z.; MOREIRA, M. R.; COUTO, E. S. O convívio acadêmico: representações sociais de alunos com Necessidades Educacionais Especiais. Revista Educação Especial, v. 29, n. 55, 2016.

SAMPAIO, R. F.; MANCINI, M. C. Estudos de revisão sistemática: um guia para síntese criteriosa da evidência científica. Revista brasileira de fisioterapia, v. 11, n. 1, p. 83-89, 2007.

SANTANA, A. P. A inclusão do surdo no ensino superior no Brasil. Journal of Research in Special Educational Needs, v. 16, p. 85-88, 2016. 
SANTOS, P. K.; DANTAS, N. M. R. Tecnologias assistivas e a inclusão do estudante surdo na educação superior. Revista Internacional de Educação Superior, v. 3, n. 3, p. 494514, 2017.

SBRANA, R. A.; CARNEIRO, R. U. C. A inclusão de alunos público-alvo da educação especial na educação superior: um estudo de caso sobre o trabalho docente com uma aluna surda no curso de pedagogia. Temas em Educação e Saúde, v. 14, n. 1, p. 121-141, 2018.

SELAU, B.; DAMIANI, M. F.; COSTAS, F. A. T. Estudantes cegos na educação superior: o que fazer com os possíveis obstáculos? Acta Scientiarum. Education, v. 39, n. 4, p. 431440, 2017.

SILVA, H. M. et al. A inclusão de estudantes com deficiência no ensino superior: Revisão de literatura. Revista Da Universidade Vale Do Rio Verde, v. 10, n. 2, p. 332-342, 2012.

SILVA, K. C.; MARTINS, S. E. S. O. Acessibilidade à educação superior brasileira: o que dizem os estudantes com deficiência. Journal of Research in Special Educational Needs, v. 16, n. S1, p. 116-119, 2016a.

SILVA, K. C.; MARTINS, S. E. S. O. ACESSIBILIDADE À EDUCAÇÃO SUPERIOR BRASILEIRA: O QUE DIZEM OS ESTUDANTES COM DEFICIÊNCIA. Journal of Research in Special Educational Needs, v. 16, p. 116-119, 2016b.

STROPARO, E. M.; MOREIRA, L. C. O papel da biblioteca universitária na inclusão de alunos com deficiência no ensino superior. Educação (UFSM), v. 1, n. 1, p. 209-222, 2016.

TEIXEIRA, M. C. T. Veloz et al. Inclusão escolar na prática de escolas inclusivas. Encontro: Revista de Psicologia, v. 11, n. 16, p. 199-222, 2015.

TEZANI, T.C. R. A relação entre gestão escolar e educação inclusiva: o que dizem os documentos oficiais? Revista online de Política e Gestão Educacional, n. 6, 2009.

TORRES; J.P.; CALHEIROS, D.S.; SANTOS, V. Inclusão na educação superior brasileira: Análise da produção cientifica. Interfaces da Educação, v.7, n.19, p.296-313, 2016.

UNESP. Câmpus Botucatu. Faculdade de ciências agronômicas. Biblioteca Paulo de Carvalho Mattos. Tipos de revisão de literatura. 2015. Disponível em: http://www.fca.unesp.br/Home/Biblioteca/tipos-de-evisao-de-literatura.pdf. Acesso em 10/10/2018.

VOSGERAU, D. S. R.; ROMANOWSKI, J. P. Estudos de revisão: implicações conceituais e metodológicas. Revista Diálogo Educacional, v. 14, n. 41, p. 165-189, 2014.

WELLICHAN, D. S. P.; SOUZA, C. S. A inclusão na prática: alunos com deficiência no Ensino Superior. Revista online de Política e Gestão Educacional, p. 146-166, 2017. 
ZILIOTTO, D. M.; SOUZA, D. J.; ANDRADE, F. I. Quando a inclusão não se efetiva: a evasão de alunos surdos ou com deficiência auditiva no ensino superior. Revista Educação Especial, v. 31, n. 62, p. 727-740, 2018.

\section{Correspondência}

Jair de Oliveira - Universidade Tecnológica Federal do Paraná. Rua: Av. Av. Alberto Carazzai, 1640 - Vila Seugling, Campus Cornélio Procópio. CEP: 86300-000. Cornélio Procópio, Paraná, Brasil.

\section{(C) $(1) \otimes$}

This work is licensed under a Creative Commons Attribution-NonCommercial 4.0 International (CC BY-NC 4.0) 